\title{
Cancer-Testis Antigen Lactate Dehydrogenase C4 in Human Cancers: Old and New Perspectives
}

\author{
Zhaolei Cui", Yingying Lin\#, Xiaoli Luo and Yan Chen* \\ Laboratory of Biochemistry and Molecular Biology Research, Fujian Provincial Key Laboratory of Tumor Biotherapy, \\ Department of Clinical Laboratory, Fujian Medical University Cancer Hospital, Fujian Cancer Hospital, PR China \\ ${ }^{\#}$ Co-first authors
}

*Corresponding author: Yan Chen, Department of Clinical Laboratory, Fujian Provincial Key Laboratory of Tumor Biotherapy, Fujian Medical University Cancer Hospital, Fujian Cancer Hospital, PR China

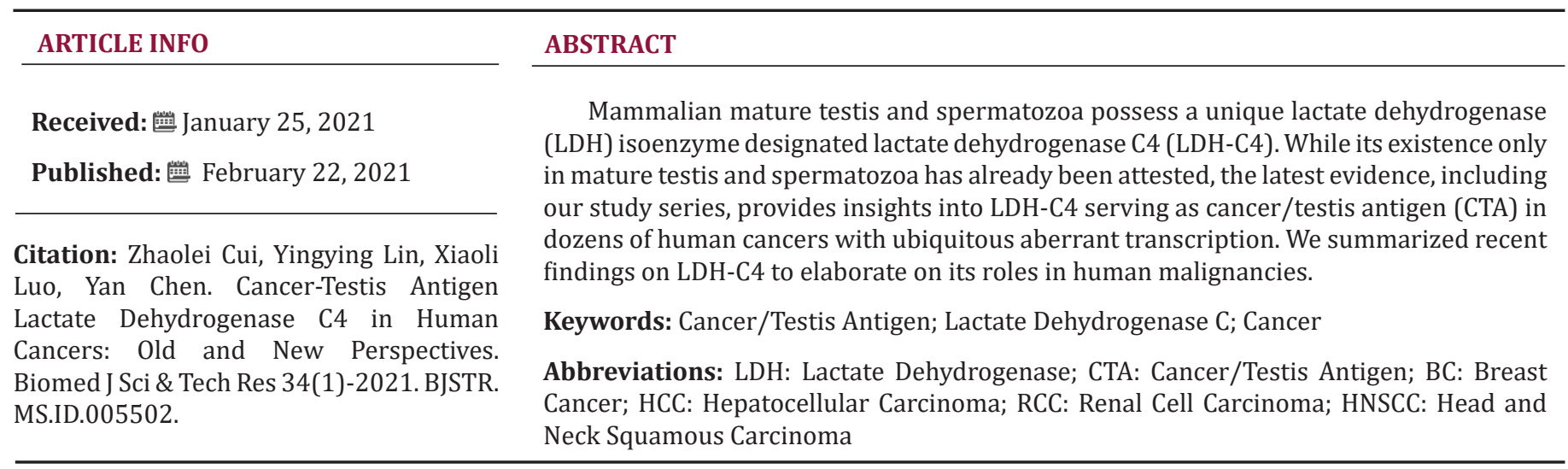

\section{Introduction}

Lactate dehydrogenase (LDH) isozymes are abundant in various mammalian tissue types and accountable for the interconversion of pyruvate and lactate during the last step of anaerobic glycolysis [1-3]. Human LDH consists of four subunits of two types, A and B, linking together to form five tetrameric isoenzymes (LDH-1 to LDH5). Following these findings, the sixth isoenzyme, designated as LDH-X, was detectable in the mature human testis in the 1960s [4,5]. LDH-X is also termed LDH-C4/LDHC as it is a tetrameric protein composed of four identical C-subunits. It, therefore, exhibits utterly distinct enzymatic, physicochemical, and immunological properties from the other isoenzymes [6-10]. Intriguingly, the current progress of LDH-C4 in human and murine reveals that though sharing high amino acid identities, human and mouse LDH-C4 are biochemically different from each other regarding some properties, particularly one that LDH-C4 is confined to mature testis, spermatocytes, spermatids, and spermatozoa [4-6, 11]. LDH-C4 is associated with glucose metabolism and is essential in the maintenance of ATP concentrations in spermatozoa [11,12-15].
Cancer/testis antigen (CTA) is, by definition, expressed only in the testis and tumor cells, absent in non-testis or noncancerous somatic cells [16]. LDH-C4 has been identified as a CTA molecule expressed in multiple malignancies, such as breast cancer (BC), lung cancer, and melanoma, with a high frequency of $47 \%$ in lung cancer, $44 \%$ in melanoma, 35\% in breast carcinoma, and $15 \%$ in colon cancer. As suggested by an underlying mechanism, $L D H C$ escapes from transcriptional repression, giving rise to significantly increased expression levels in a wide range of human tumor entities [17]. Our study series ascertained LDHC/LDH-C4 expressions in BC $[18,19]$, liver cancer [20], nasopharyngeal carcinoma, lung cancer, and osteosarcoma and its predictive power as a biomarker [21]. Based on the latest discovery and our previous findings, emphasis will be given to the roles of LDH-C4 in human tumors.

\section{LDH-C4 and Breast Cancer}

Our BC research using an LDH-C4 inhibitor N-propyl oxamate has proven that endogenous LDH-C4 inhibition is crucial in the 
exuberant invasion and metastasis of MDA-MB-231 BC cells [18]. However, this effect did not occur in LDH-C4-negative MCF-7 BC cells. Koslowski, et al. have found that the positive rate of $L D H C$ in $\mathrm{BC}$ tissues is 35\% [17]. But our results demonstrated much higher positive rates of serum and exosomal $L D H C$ mRNA expressions of 91.66\% (22/24) and $87.50 \%(21 / 24)$ in BC patients, respectively, versus the rates as low as $9.16 \%(11 / 120)$ and $6.67 \%(8 / 120)$ in healthy controls; the average LDH-C4 expression in the serum and exosomes of newly diagnosed BC cases were 9.79 and 8.87 folds of healthy controls [19]. Moreover, as the AUC values of serum and exosomal $L D H C$ expression in discriminating $\mathrm{BC}$ from noncancerous specimens were 0.9587 and 0.9464 , it could be used as a strong index for BC diagnosis [19].

Serum and exosomal $L D H C$ levels are also associated with tumor size and HER2 and Ki-67 expressions in BC and with treatment efficacy and relapse, featuring a remarkable reduction in $L D H C$ expression levels after the treatment or rebound $L D H C$ levels since relapse [19]. By using high-throughput tissue microarray combined with the immunohistochemical assay, our finding demonstrated LDH-C4 protein expressions in BC tissues and their correlation with clinicopathological characteristics and BC prognosis [19]. LDH-C4 protein expression was predominantly detectable in the cytoplasm of $\mathrm{BC}$ cells but sparsely expressed in some nuclei. The positive rate of $\mathrm{LDH}-\mathrm{C} 4$ in $\mathrm{BC}$ tissues was $91.55 \%$, including low $\mathrm{LDH}-\mathrm{C} 4$ expression $(-/+)$ in $33.10 \%$ of $\mathrm{BC}$ tissues and high expression $(+/++)$ in $66.90 \%$ of $\mathrm{BC}$ tissues. About $89 \%$ of adjacent normal tissues were free of LDH-C4, leaving only $11 \%$ with low LDH-C4 expression $(-/+)[19]$. Together with the survival analysis results that patients with high LDH-C4 levels were at higher risk of a poor prognosis, LDH-C4 is a useful indicator for prognosis prediction in BC.

\section{LDH-C4 and Lung Cancer}

Grunwald, et al. detected the mRNA expression levels of 7 CTAs (including LDHC) in NSCLC tissues and cell lines, and the positive rate of $L D H C$ expression reached $25 \%$ in NSCLC tissues and completely undetectable in normal pulmonary specimens [22]. Histopathological subtyping revealed that $L D H C$ mRNA was expressed in a high proportion of adenocarcinoma, squamous cell carcinoma, and large cell carcinoma. They recommended the paired biomarker analysis of $L D H C$ and CG genes for greater diagnostic power in NSCLC and used $L D H C$ as a new tool for monitoring immunotherapy [22]. A study by Yen, et al. connected $L D H C$ expression to cigarette smoking habits in lung cancer patients, especially in male patients with pleural effusion; the property of the aberrant $L D H C$ expression between tumor entities of lung cancer makes the gene sensitive in predicting early-onset types like smoking-related lung adenocarcinoma [23]. The upregulation of $L D H C$ gene expression is such a critical risk factor of lung cancer that LDH-C4 can serve as a potential marker for its diagnosis [23].
Consistently, our study with tissue microarrays also revealed that a high positive rate of LDH-C4 expression in adenocarcinoma of the lung of above $80 \%$ (unpublished data). Based on risk stratification, Kaplan-Meier curves disclosed a poor prognosis in patients with LDH-C4 overexpression (unpublished data). Correspondingly, a newly published study also confirmed that $L D H C$ expression was significantly correlated with a poor prognosis of the lung adenocarcinoma patients; moreover, $L D H C$ could promote proliferation, migration, invasion, and EMT in lung adenocarcinoma cells by triggering the PI3K/Akt/GSK-3 $\beta$ pathway [24].

\section{LDH-C4 and Renal Cell Carcinoma}

A study by Hua, et al. ascertained the relationship between LDH-C4 and clinical staging in renal cell carcinoma (RCC) [25]. Increased LDH-C4 expression indicated 'ferocious' invasion and metastasis of RCC cells and short-term survival, putting RCC patients at high risk of poor prognosis. So LDH-C4 may involve in both carcinogenic and malignant transformation regarding this primary malignant type [25]. Li, et al. utilized LDH-C4 down-expression in CAKI-1 RCC cells by siRNA silencing and found lowly expressed LDH-C4 markedly reduced the number of cells passing through a Matrigel-coated filter membrane, confirming the invasive and migrating potentials of LDH-C4-positive RCC cells indirectly [26]. Other studies of screening proteins related to cancer cell invasion and metastasis reported that endogenous LDH-C4 enhanced matrix metalloproteinase-9 (MMP-9) expression and lactic acid production, increasing the invasion and migration of malignant RCC cells [21,27,28]. Also, tumor-associated fibroblasts induced by substantial lactic acid build-up may propel hyaluronic acid secretion, creating an environment for the invasion and migration of aggressive RCC cells as well as exuberant metastasis [21].

\section{LDH-C4 and Nasopharyngeal Carcinoma (NPC)}

LDHC mRNA expression was proved undetectable in patients with head and neck squamous carcinoma (HNSCC) based on the analysis of CTA expression data from 51 cases [29]. However, our unpublished data showed that LDH-C4 protein was abundant in NPC tissues, particularly in the cytoplasm of NPC cells. LDHC4-positive specimens accounted for $88.4 \%$ (114/129) of NPC patients, and cases of low (-/+) and high LDH-C4 expression (+/++) possessed 49.6\% (64/129) and 50.4\% (65/129), respectively. The tissue-specific LDH-C4 expression is also associated with clinicopathological manifestations, such as clinical staging and cervical lymphatic metastasis (unpublished data). The upregulation of LDH-C4 expression also links to shorter survival and a poorer prognosis in NPC versus patients with a low LDH-C4 level (unpublished data). This effect may be attributed to the underlying mechanism of accelerated growth, colony formation, and migration of CNE2 cells (a poorly differentiated NPC cell line) mediated by the rise of LDH-C4 expression (unpublished data). 


\section{LDH-C4 and Other Malignant Tumors}

$L D H C$ gene is also differentially expressed in melanoma and prostatic cancer and noncancerous specimens, implying its role in the occurrence and development of the two cancer types [17]. A study reported $L D H C$ expression inhibition in osteosarcoma and that its complete transcript and metabolic characteristics were conducive to the early detection and diagnosis of osteosarcoma with high accuracy [30]. Our data for $L D H C$ gene expression in hepatocellular carcinoma (HCC) demonstrated that 68\% and $60 \%$ LDHC-positive specimens were detectable in the serum and serum-derived exosomes, showing AUCs of serum and exosomal LDHC in differentiating HCC from noncancerous controls of 0.8382 and 0.9451 , respectively [20]. Consistently, LDH-C4 protein overexpression was found sensitive in predicting a poor prognosis of HCC patients [20]. Some studies have disclosed the aberrant $L D H C$ transcript amplified in spermatocytic seminomas, osteosarcoma, and some melanoma [30-32]. Generally, the differentially expressed $L D H C$ gene is detectable across various cancer types, and the expression status as well as the biological functions were summarized in Table 1.

Table 1: LDHC/LDH-C4 expressions and functions in human cancer types based on published studies.

\begin{tabular}{|c|c|c|}
\hline Cancers & LDHC/LDH-C4 Expressions and Functions & References \\
\hline $\begin{array}{l}\text { Melanoma, breast, colon, prostate, lung, renal, } \\
\text { ovarian, thyroid, cervical cancers; melanoma } \\
\text { and lung cancer cell lines }\end{array}$ & $\begin{array}{l}\text { Frequencies of } L D H C \text { expression in cancers: melanoma }(7 / 16) \text {, breast }(7 / 20) \text {, colon } \\
(3 / 20) \text {, prostate }(3 / 8) \text {, lung }(8 / 17) \text {, renal }(4 / 7) \text {, ovarian }(3 / 7) \text {, thyroid }(1 / 4) \text {, and } \\
\text { cervical cancers }(5 / 6) \text {; melanoma }(5 / 8) \text { and lung cancer cell lines }(2 / 6) . L D H C \\
\text { activation was mediated by neither gene promotor demethylation nor hypoxia }\end{array}$ & {$[17]$} \\
\hline Melanoma cell lines (A375M and C81-61) & $\begin{array}{l}\text { CpG island hypomethylation and transcription factor Sp1 and CREB were found to } \\
\text { play a major role in } L D H C \text { transcription }\end{array}$ & {$[30]$} \\
\hline Lung adenocarcinoma & $\begin{array}{c}L D H C \text { served as a candidate oncogene in the carcinogenesis of smoking-related lung } \\
\text { adenocarcinoma }\end{array}$ & {$[23]$} \\
\hline Non-small cell lung cancer & $\begin{array}{c}25 \% \text { cases were } L D H C \text {-positive; } L D H C \text { could not be activated by genomic } \\
\text { hypomethylation; LDH-C4 is a prognostic factor; LDHC enhanced proliferation, } \\
\text { migration, invasion, and EMT in lung adenocarcinoma cells by triggering the PI3K/ } \\
\text { Akt/GSK-3 } \beta \text { pathway }\end{array}$ & {$[22,24]$} \\
\hline Hepatocellular carcinoma & $\begin{array}{l}68 \% \text { and } 60 \% \text { of serum and exosomal } L D H C \text {-positive cases; patients with high } \\
\text { LDH-C4 expression }(++/+++) \text { in HCC tissues accounted for } 55.84 \% \text {. LDHC/LDH-C4 } \\
\text { as a useful biomarker for early diagnosis, efficacy evaluation, relapse monitoring, and } \\
\text { prognosis prediction for HCC }\end{array}$ & {$[20]$} \\
\hline Breast cancer & $\begin{array}{l}91.66 \% \text { and } 87.50 \% \text { of serum and exosomal } L D H C \text {-positive cases and } 91.55 \% \text { of } \mathrm{LDH}- \\
\text { C4-positive patients. } \mathrm{LDHC} / \mathrm{LDH}-\mathrm{C} 4 \text { exhibited high discrimination power in diagnosis, } \\
\text { efficacy evaluation, relapse monitoring, and prognosis prediction for BC }\end{array}$ & {$[18,19]$} \\
\hline Spermatocytic seminomas & $L D H C$ was specifically expressed in spermatocytic seminomas & {$[32]$} \\
\hline Osteosarcoma & $L D H C$ was differentially expressed in osteosarcoma and normal specimens & {$[30]$} \\
\hline
\end{tabular}

\section{Conclusion and Perspectives}

Despite the conventional understanding of LDH-C4 as a key isoenzyme essential for sperm motility, capacitation, and fertilization, its encoding gene $L D H C$ is a CTA family member and a potential therapeutic target of immunotherapy against several cancer types. The aberrant $L D H C$ transcription predominantly participates in malignant behaviors, serving as a sensitive marker in tumor onset, development, and progression. However, the current evidence for LDHC's roles in cancer patients is insufficient, and what we have yet to discover includes other diverse biofunctions of LDH-C4 across various cancer types in patients, which require large-sample clinical studies with multiple independent sources.

\section{Acknowledgement}

This study was supported by the National Natural Science Foundation of China (Grant number: 81802631), Provincial Natural Science Fund of Fujian (Grant no. 2018J01273), and Science and Technology Program of Fujian Province, China (Grant no. 2018Y2003).

\section{Competing Interests}

The authors have declared that no competing interest exists.

\section{References}

1. Echigoya $Y$, Sato T, Itou T, Endo H, Sakai T (2009) Molecular characterization and expression pattern of the equine lactate dehydrogenase A and B genes. Gene 447(1): 40-50.

2. Edmunds RC, van Herwerden L, Smith Keune C, Jerry DR (2009) Comparative characterization of a temperature responsive gene (lactate dehydrogenase-B, ldh-b) in two congeneric tropical fish, Lates calcarifer and Lates niloticus. Int J Biol Sci 5(6): 558-569.

3. Adeva Andany M, López Ojén M, Funcasta Calderón R, Ameneiros Rodríguez E, Donapetry García C, et al. (2014) Comprehensive review on lactate metabolism in human health. Mitochondrion 17: 76-100.

4. Goldberg E (1963) Lactic and Malic Dehydrogenases in Human Spermatozoa. Science 139(3555): 602-603. 
5. Blanco A, Zinkham WH (1963) Lactate Dehydrogenases in Human Testes. Science 139(3555): 601-602.

6. Goldberg E, Eddy EM, Duan C, Odet F (2010) LDHC: the ultimate testisspecific gene. J Androl 31(1): 86-94.

7. Goldberg E (1972) Amino acid composition and properties of crystalline lactate dehydrogenase X from mouse testes. J Biol Chem 247(7): 20442048.

8. LeVan KM, Goldberg E (1991) Properties of human testis-specific lactate dehydrogenase expressed from Escherichia coli. Biochem J 273( Pt 3): 587-592.

9. Goldberg E, VandeBerg JL, Mahony MC, Doncel GF (2001) Immune response of male baboons to testis-specific LDH-C(4). Contraception 64(2): 93-98.

10. Hawtrey CO, Goldberg E (1970) Some kinetic aspects of sperm specific lactate dehydrogenase in mice. J Exp Zool 174(4): 451-461.

11. Hintz M, Goldberg E (1977) Immunohistochemical localization of LDH-X during spermatogenesis in mouse testes. Dev Biol 57(2): 375-384.

12. Cordero Martínez J, Aguirre Alvarado C, Wong C, Rodríguez Páez L (2014) Effect of oxamic analogues on functional mice sperm parameters. Syst Biol Reprod Med 60(4): 189-198.

13. Odet F, Duan C, Willis WD, Goulding EH, Kung A, et al. (2008) Expression of the gene for mouse lactate dehydrogenase $\mathrm{C}$ (Ldhc) is required for male fertility. Biol Reprod 79(1): 26-34.

14. Odet F, Gabel SA, Williams J, London RE, Goldberg E, et al. (2011) Lactate dehydrogenase $\mathrm{C}$ and energy metabolism in mouse sperm. Biol Reprod 85(3): 556-564.

15. Odet F, Gabel S, London RE, Goldberg E, Eddy EM (2013) Glycolysis and mitochondrial respiration in mouse LDHC-null sperm. Biol Reprod 88(4): 95.

16. Salmaninejad A, Zamani MR, Pourvahedi M, Golchehre Z, Hossein Bereshneh A, et al. (2016) Cancer/Testis Antigens: Expression, Regulation, Tumor Invasion, and Use in Immunotherapy of Cancers. Immunol Invest 45(7): 619-640.

17. Koslowski M, Tureci O, Bell C, Krause P, Lehr HA, et al. (2002) Multiple splice variants of lactate dehydrogenase $\mathrm{C}$ selectively expressed in human cancer. Cancer Res 62(22): 6750-6755.

18. Kong L, Du W, Cui Z, Wang L, Yang Z, et al. (2016) Expression of lactate dehydrogenase $C$ in MDA-MB-231 cells and its role in tumor invasion and migration. Mol Med Rep 13(4): 3533-3538.

19. Cui Z, Chen Y, Hu M, Lin Y, Zhang S, et al. (2020) Diagnostic and prognostic value of the cancer-testis antigen lactate dehydrogenase C4 in breast cancer. Clin Chim Acta 503: 203-209.

20. Cui Z, Li Y, Gao Y, Kong L, Lin Y, et al. (2020) Cancer-testis antigen lactate dehydrogenase $\mathrm{C} 4$ in hepatocellular carcinoma: a promising biomarker for early diagnosis, efficacy evaluation and prognosis prediction. Aging (Albany NY) 12(19): 19455-19467.

21. Lin Y, Zhou F, Chen Y, Cui Z (2019) Research progress of lactate dehydrogenase C4 in malignant tumors. Chinese Journal of Oncology Prevention and Treatment 11(6): 528-531.

22. Grunwald C, Koslowski M, Arsiray T, Dhaene K, Praet M, et al. (2006) Expression of multiple epigenetically regulated cancer/germline genes in nonsmall cell lung cancer. Int J Cancer 118(10): 2522-2528.

23. Yen CC, Liang SC, Jong YJ, Chen YJ, Lin CH, et al. (2007) Chromosomal aberrations of malignant pleural effusions of lung adenocarcinoma: different cytogenetic changes are correlated with genders and smoking habits. Lung cancer 57(3): 292-301.

24. Chen L, Wu Q Xu X, Yang C, You J, et al. (2021) Cancer/testis antigen LDHC promotes proliferation and metastasis by activating the PI3K/ Akt/GSK-3 $\beta$-signaling pathway and the in lung adenocarcinoma. Exp Cell Res 398(2): 112414

25. Hua Y, Liang C, Zhu J, Miao C, YuY, et al. (2017) Expression of lactate dehydrogenase $C$ correlates with poor prognosis in renal cell carcinoma. Tumour biology 39(3): 1010428317695968.

26. Li S, Zhang L, Wang S, Qing C, Yin C (2015) Effect of cancer-testis antigen LDHC on the invasion and metastasis of renal cell carcinoma. Journal of Modern Urology 20(10): 737-740.

27. Sun GG, Wei CD, Jing SW, Hu WN (2014) Interactions between filamin A and MMP-9 regulate proliferation and invasion in renal cell carcinoma. Asian Pac J Cancer Prev 15(8): 3789-3795.

28. Sato A, Nagase H, Obinata D, Fujiwara K, Fukuda N, et al. (2013) Inhibition of MMP-9 using a pyrrole-imidazole polyamide reduces cell invasion in renal cell carcinoma. Int J Oncol 43(5): 1441-1446.

29. Atanackovic D, Blum I, Cao Y, Wenzel S, Bartels K, et al. (2006) Expression of cancer-testis antigens as possible targets for antigen-specific immunotherapy in head and neck squamous cell carcinoma. Cancer Biol Ther 5(9): 1218-1225.

30. Chen K, Zhu C, Cai M, Fu D, Cheng B, et al. (2014) Integrative metabolome and transcriptome profiling reveals discordant glycolysis process between osteosarcoma and normal osteoblastic cells. J Cancer Res Clin Oncol 140(10): 1715-1721.

31. Tang H, Goldberg E (2009) Homo sapiens lactate dehydrogenase c (Ldhc) gene expression in cancer cells is regulated by transcription factor Sp1, CREB, and CpG island methylation. J Androl 30: 157-167.

32. Looijenga LH, Hersmus R, Gillis AJ, Pfundt R, Stoop HJ, et al. (2006) Genomic and expression profiling of human spermatocytic seminomas: primary spermatocyte as tumorigenic precursor and DMRT1 as candidate chromosome 9 gene. Cancer Res 66(1): 290-302.
ISSN: 2574-1241

DOI: 10.26717/BJSTR.2021.34.005502

Yan Chen. Biomed J Sci \& Tech Res

This work is licensed under Creative

Commons Attribution 4.0 License

Submission Link: https://biomedres.us/submit-manuscript.php

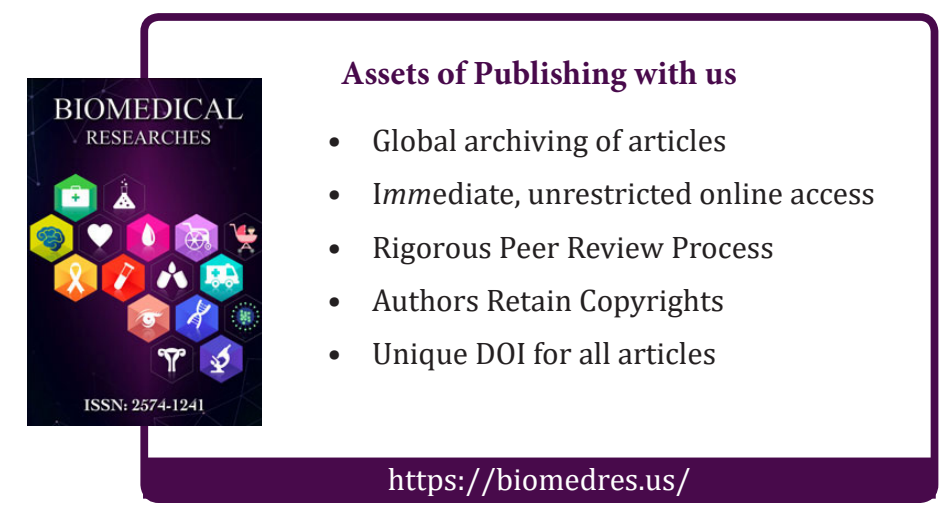

